\title{
INVESTIGAÇÃO-AÇÃO E ANÁLISE DE CONTEÚDO: CASO NA FORMAÇÃO DE PROFESSORES
}

\author{
ACTION RESEARCH AND CONTENT ANALYSIS: CASE IN TEACHER EDUCATION
}

\author{
INVESTIGACIÓN-ACCIÓN Y ANÁLISIS DE CONTENIDO: CASO EN LA \\ FORMACIÓN DE PROFESORES
}

\author{
Ana Luísa Rodrigues \\ Instituto de Educação, Universidade de Lisboa - Portugal
}

\begin{abstract}
Resumo: A investigação-ação enquanto metodologia de investigação qualitativa no contexto educacional pode contribuir para um questionamento reflexivo e coletivo com vista ao melhoramento das práticas pedagógicas, para a compreensão sobre essas práticas e situações nas quais estas foram desenvolvidas e, consequentemente, para o desenvolvimento profissional docente. Na recolha e tratamento dos dados, a análise de conteúdo apresenta-se como um método privilegiado na análise de dados qualitativos que inclui um conjunto de técnicas que permitem cumprir de forma mais rigorosa e objetiva os critérios de cientificidade e a validação da construção do conhecimento. Este artigo, através de uma revisão de literatura e análise de um caso, pretende compreender como pode ser aplicada a metodologia de investigação-ação em estudos de investigação no contexto educacional, especificamente na formação de professores, e verificar a importância que assume o método de análise de conteúdo na qualidade de uma investigação qualitativa. $\mathrm{O}$ caso apresentado constitui-se por um projeto de investigação-formação desenvolvido numa comunidade educativa com o objetivo de promover a inovação de metodologias e estratégias pedagógicas através da aplicação de um programa de formação ativa de professores com integração das tecnologias digitais. Neste projeto confirmou-se o desenvolvimento de uma cultura mais digital nesta comunidade educativa, propiciadora do desenvolvimento profissional docente no contexto da futura sociedade do conhecimento, constando-se a adequação da metodologia de investigação proposta.
\end{abstract}

Palavras chave: Investigação-ação; Análise de conteúdo; Formação de professores.

\begin{abstract}
Action research as a qualitative research methodology in the educational context can contribute to a reflective and collective questioning with a view to improving pedagogical practices, to the understanding of these practices and situations in which they were developed and, consequently, to the professional development of teachers. In data collection and processing, content analysis is a privileged method in the analysis of qualitative data which includes a set of techniques that allow a more rigorous and objective compliance with the scientific criteria and validation of knowledge construction. This article, through a literature review and a case analysis, aims to understand how the action research methodology can be applied in research studies in the educational context, specifically in teacher education, and to verify the importance of the content analysis method in the qualitative research quality. The case presented consists of a research-training project developed in an educational community with the objective of promoting the innovation of methodologies and pedagogical strategies through the application of a program of active teacher education with the integration of digital technologies. This
\end{abstract}


project confirmed the development of a more digital culture in this educational community, fostering the professional development of teachers in the context of the future knowledge society, confirming the appropriateness of the proposed research methodology.

Keywords: Action research; Content Analysis; Teacher education.

Resumen: La investigación-acción como metodología de investigación cualitativa en el contexto educativo puede contribuir a un cuestionamiento reflexivo y colectivo con vistas a mejorar las prácticas pedagógicas, a la comprensión de estas prácticas y de las situaciones en las que se desarrollaron y, en consecuencia, al desarrollo profesional de los docentes. En la recogida y tratamiento de datos, el análisis de contenido es un método privilegiado en el análisis de datos cualitativos que incluye un conjunto de técnicas que permiten un cumplimiento más riguroso y objetivo de los criterios de cientificidad y validación de la construcción del conocimiento. Este artículo, a través de una revisión bibliográfica y del análisis de un caso, pretende comprender cómo la metodología de la investigación-acción puede aplicarse en estudios de investigación en el contexto educativo, concretamente en la formación de profesores, y comprobar la importancia del método de análisis de contenido en la calidad de una investigación cualitativa. El caso presentado consiste en un proyecto de investigación-formación desarrollado en una comunidad educativa con el objetivo de promover la innovación de metodologías y estrategias pedagógicas mediante la aplicación de un programa de formación activa del profesorado con la integración de tecnologías digitales. Este proyecto confirmó el desarrollo de una cultura más digital en esta comunidad educativa, fomentando el desarrollo profesional de los profesores en el contexto de la futura sociedad del conocimiento, confirmando la idoneidad de la metodología de investigación propuesta.

Palabras clave: Investigación-acción; Análisis de contenido; Formación de profesores.

\section{Introdução}

Podemos diferenciar o designado conhecimento vulgar do conhecimento científico pela forma como se obtém este conhecimento, isto é, através da aplicação de um determinado método, que se exige: objetivo, racional, sistemático, comparável, fático, analítico, comunicável e metódico (LUKAS; SANTIAGO, 2004).

Segundo estes autores, a cientificidade atribuída à educação não se pode desligar da interdisciplinaridade e devemos ter em conta que:

[...] o mundo das ciências da natureza é diferente do mundo das ciências sociais que estudam os fenómenos do ser humano enquanto parte integrante de um grupo social. Nestes dois mundos, os pressupostos de partida são diferentes, assim como, terão que ser também diferentes as formas de investigar estes fenómenos, tendo em atenção que os fenómenos sociais são multivariáveis, permeáveis aos valores e à multidisciplinariedade. (LUKAS; SANTIAGO, 2004, p.19)

No contexto da educação e formação, considera-se que professores e alunos definem conjuntamente o mundo real nas suas interações, adquirindo potencial para se modificarem, 
tanto a eles próprios como ao meio, transformando-se em agentes de mudança, com efeitos nos fenómenos e entorno social.

A abordagem através da metodologia de investigação-ação, segundo Bogdan e Biklen (1994), é útil em programas de formação de professores porque permite explorar o ambiente complexo das escolas e simultaneamente torna os professores mais autoconscientes dos seus próprios valores e da forma como estes influenciam as suas atitudes.

Neste sentido, através de uma revisão de literatura e análise de um caso, pretendeu-se compreender como a metodologia de investigação-ação pode ser desenvolvida em estudos de investigação no contexto educacional, e mais especificamente na formação de professores, e a importância da técnica de análise de conteúdo a esta associada no âmbito qualitativo da investigação.

\section{A investigação qualitativa em Educação}

Ao longo da História denota-se uma ênfase na "quantificação" da ciência, porém, com o desenvolvimento das ciências sociais e a maior utilização de dados qualitativos, novos e diferentes paradigmas têm sido propostos (GUBA; LINCOLN, 1994).

Assumindo, epistemologicamente, o mundo "real" como uma forma múltipla e holística, com construções mentais intangíveis e flexíveis, baseadas no social e na experiência, com uma visão da realidade transacional e subjetivista, considera-se que o investigador e o objeto da investigação estão ligados de forma interativa. Ou seja, a realidade não é apenas definida pela existência de múltiplas variáveis em interação em cada contexto, mas o que se distingue como sua caraterística base é o caráter coerente e organizado dos fenómenos sociais que, não sendo o todo a soma das partes, integram ideias, crenças e normas sociais, sendo os indivíduos agentes ativos na construção da realidade social subjetivista (RODRIGUES, 1992).

Seguindo Guba e Lincoln (1994, pp.105-106), parte-se da questão ontológica "como são as coisas realmente?" e "como na realidade funcionam?", assumindo o mundo "real" uma forma múltipla, com construções mentais intangíveis ou realidades flexíveis, baseadas no social e na experiência, e epistemologicamente de uma visão da realidade transacional e subjetivista, em que o investigador e o objeto da investigação estão ligados de forma interativa e os resultados são literalmente criados como procedimentos da investigação, diluindo-se a distinção convencional entre ontologia e epistemologia.

Nesta abordagem, a natureza variável e pessoal das construções sociais sugere que as construções individuais são desenvolvidas através de interação entre o investigador e os participantes da investigação, sendo estas construções depois interpretadas e comparadas 
através de um intercâmbio dialético entre ambos. Neste sentido, num paradigma naturalista, a realidade é vista como múltipla, intangível, divergente e holística, com uma forte inter-relação entre investigador e participantes, dependentes de valores, com hipóteses e afirmações relativas a um determinado contexto e padrões de atributos interativos (LINCOLN; GUBA, 1985).

Por outro lado, considerando que o ser humano deve ser colocado sempre em função dos objetos que constrói e que o constroem como um objeto social, na perspectiva do interacionismo simbólico, segundo (GIRALDO-RAMÍREZ, 2009),

[...] a consciência de si mesmo e o reconhecer-se a si mesmo, é uma condição prévia da experiência e é o que o torna um agente da sua própria vida como sujeito-objeto numa relação dialética. O ser humano, como agente, é mais reflexivo do que reativo, uma vez que não se limita a responder a uma presença ou percepção, mas atua em relação a esta através de um processo interpretativo. Este caráter reflexivo é o que faz da interpretação um processo dinâmico e contínuo de aprendizagem sobre o mundo, onde os objetos também são redefinidos continuamente. (p.110)

De acordo com Carvalho, Borges e Rêgo (2010), as raízes teóricas do interacionismo simbólico são muito complexas e apresentam diferentes influências filosóficas, destacando-se a influência da Escola de Chicago e dos trabalhos de Dewey (1960) e de George Mead. Blumer (1982) sustentado nos conceitos teóricos de Mead, afirma que o mundo empírico é o ponto de partida e que para o compreender é necessário observá-lo, estudá-lo e analisá-lo em termos das ações e interações dos seus participantes, defendendo que a "realidade" só existe no mundo empírico, onde deverá ser procurada e verificada. Critica inclusive muitos procedimentos que defendem a necessidade de utilização de técnicas estatísticas e quantitativas, pois ignoram aspetos como os pressupostos, problemas e conceitos, limitando o ato completo da investigação.

De um modo geral, podemos dizer que o interacionismo simbólico possibilita a compreensão da forma como os indivíduos interpretam os objetos e as outras pessoas com as quais interagem e como este processo de interpretação conduz ao comportamento em situações específicas. Desta forma, é considerada uma das abordagens mais adequadas para analisar processos de socialização, ressocialização, de mobilização de mudança de opiniões, de comportamentos, expetativas e exigências sociais (CARVALHO ET AL., 2010).

Por outro lado, em termos epistemológicos, o interacionismo simbólico veicula-se com o paradigma interpretativo, na medida em que se aproxima mais de estudos a um nível micro, sem pretensões de generalização, o que não quer dizer que estes sejam menos rigorosos e exigentes, mas sim qualitativamente mais profundos, segundo Giraldo-Ramírez (2009).

Por outro lado, também o paradigma crítico se pode justificar numa abordagem qualitativa. Este pretende questionar, refletir e agir sobre o status quo estabelecido para alcançar 
uma mudança sobre as práticas pedagógicas no contexto educativo e procura o rigor e profundidade da interpretação da realidade para uma ação mais eficaz, incorporando características do paradigma interpretativo.

De acordo com Lukas e Santiago (2004), “outras denominações são comuns relativas ao paradigma crítico, como paradigma socio crítico, investigação-ação ou ciência crítica, (...) este paradigma parte da crítica a uma situação com o objetivo de construir outras situações ou realidades mais justas" (p.30). É de salientar que, "no campo educativo, este paradigma tem trazido contributos aos modelos de ação no campo da formação e desenvolvimento profissional dos professores”, segundo Escudero (1990), citado em Lukas e Santiago (2004, p.33).

Rodríguez (2007) caracteriza-o como um paradigma que promove a compreensão da realidade para a sua transformação, numa lógica de dinâmica de evolução e interação, que pode utilizar métodos qualitativos e quantitativos, e considerando que a ciência implica a emancipação da razão e a incorporação de valores para a ação transformadora baseada na dialética entre teoria e práxis.

Assim, entendemos a investigação qualitativa, não como uma recolha de "factos" sobre o comportamento humano para elaborar uma teoria e estabelecer relações de causalidade para predizer comportamentos, mas considerando que esta abordagem pode dificultar "a capacidade de apreender o carácter essencialmente interpretativo da natureza e experiência humanas", pelo que o objetivo será "compreender o processo mediante o qual as pessoas constroem significados e descrever em que consistem esses mesmos significados" (BOGDAN; BIKLEN, 1994, p.70).

Estes autores defendem que a investigação-ação pode ser usada em variadas áreas, designadamente, para a inovação dos métodos de ensino, diversificação de estratégias de aprendizagem, procedimentos de avaliação e desenvolvimento profissional contínuo (COHEN; MANION; MORRISON, 2000, FONSECA, 2013). Assim, a investigação-ação deve combinar ciclos de ação com identificação do problema, planeamento e implementação da intervenção e avaliação dos resultados; uma prática reflexiva; emancipação política; teoria crítica; desenvolvimento profissional; e investigação participativa das práticas.

Questionando a objetividade da abordagem de investigação-ação, Bogdan e Biklen (1994), não assumindo nenhum ponto de vista particular, acreditam que esta objetividade se relaciona com: a integridade do investigador e a honestidade; o detalhe e rigor usado por este no relato das observações realizadas; e ainda, com a obtenção da perspectiva de todas as partes envolvidas nas questões.

Deste modo, a investigação em ciências da educação deve estar sujeita a critérios de validade (ou credibilidade), transferibilidade, confiança e confirmabilidade de construção do 
conhecimento (GUBA, 1983) e cumprir critérios de cientificidade normalizados, demonstrando que é possível dominar os processos de construção do conhecimento científico.

Também não deve ser dispensada a ética da construção da verdade possível assente em critérios de rigor (ESTRELA, 2007). Toda a investigação educacional deve ser conduzida com ética no respeito pela pessoa, pelo conhecimento, pelos valores democráticos, pela qualidade da investigação educacional e pela liberdade académica. Estes princípios devem ainda seguir orientações éticas de respeito para com os participantes, diferentes intervenientes na investigação e público em geral, nomeadamente ao nível do consentimento informado, quanto ao direito de estes serem informados adequadamente sobre os objetivos, procedimentos e resultados da investigação (BERA, 2018; BOGDAN; BIKLEN, 1994; COHEN ET AL., 2000).

De acordo com Bogdan e Biklen (1994), a investigação qualitativa possui cinco características que a definem: considera que a fonte direta dos dados é o ambiente natural num contexto determinado, sendo o investigador um dos principais instrumentos; os dados recolhidos são descritivos, em forma de palavras ou imagens, por norma minuciosos, procurando analisar toda a sua riqueza; coloca a ênfase mais nos processos que nos resultados ou produtos; o processo de análise de dados não é fechado desde o início, mas sim, a análise dos dados é realizada de forma indutiva, construindo abstrações à medida que os dados são recolhidos e agrupados; reconhece a importância do significado e apreensão adequada das diferentes perspectivas e modo como os participantes interpretam estes significados, com uma espécie de "diálogo" entre os investigadores e os sujeitos.

Deste modo, a opção por uma investigação de natureza qualitativa deve considerar-se quando estamos perante uma realidade construída por diferentes pessoas em interação enquanto vivem as suas vidas, podendo estas ter um papel ativo na construção e modificação do "mundo real" (BOGDAN; BIKLEN, 1994),

Em suma, partindo-se de um paradigma mais interpretativo ou mais crítico, a ênfase na investigação-ação como opção metodológica no contexto educativo justifica-se pelo facto de esta ser caraterizada por uma maior proximidade do real pela predominância da práxis, pela participação e pela reflexão crítica e intencionalidade transformadora, segundo Stenhouse (1993) citado em Coutinho, Sousa, Dias, Bessa, Ferreira e Vieira (2009), tendo como propósito questionar as práticas e os valores e articular investigação, ação e formação.

\section{A investigação-ação e importância da análise de conteúdo}

A metodologia de Investigação-Ação (IA) nasceu nos Estados Unidos da América, na década de 40 do século passado. Foi nomeada por Kurt Lewin, quando afirmou que "É um tipo 
de investigação-ação, uma investigação comparativa sobre as condições e efeitos de várias formas de ação social, e investigação conducente à ação social. A investigação que só produz livros não será suficiente" (LEWIN, 1946, p.35).

Este acreditava que se podiam efetuar mudanças efetivas através do processo de investigação, reflexão e autoquestionamento, integrando a experimentação científica e a ação social. Definiu a IA como um processo cíclico de exploração, atuação e validação de resultados, que pretendia uma mudança de atitude nos grupos sociais através do envolvimento coletivo nas decisões e processos de investigação, que no campo educacional, deveria ser conduzida pelos próprios professores (SCHNETZLER, 2019).

Diversos autores, entretanto, seguiram e trabalharam sobre esta metodologia de investigação que se pretende que seja "colaborativa e desenvolvida através da ação analisada criticamente pelos vários elementos do grupo" (KEMMIS; MCTAGGART, 1988, p.5).

Segundo Caetano (2004b),

[...] quando se conjugam princípios de ação em dispositivos de formação que se podem investigar e transformar, a ação pode ser utilizada como um processo de investigação desses princípios e dessa ação, e a investigação como um processo de transformação da ação. (p. 227)

Assim, neste tipo de investigação-ação ou investigação-formação, quando nos referimos à sua aplicação em processos de formação, pretende-se interrogar, analisar, desafiar, refletir e reconstruir saberes e conhecimentos, enquadrado num ambiente colaborativo, que se faz "caminhando" com os outros num processo de construção interativo de percursos pessoais e profissionais e percursos de formação, enquanto objetos de análise e transformação.

A questão da reflexão assume um papel preponderante na investigação-ação, de acordo com Caetano (2003), na medida em que vem possibilitar a negociação com os professores, assim como a adaptação aos diferentes contextos, tratando-se de um processo de investigação contextualizado que parte da análise da realidade educativa, das suas necessidades e problemas, procurando responder-lhes (FONSECA, 2013).

Ao facilitar o desenvolvimento da reflexividade, seja ao nível do pensamento, seja ao nível da ação, podemos obter uma melhor compreensão da complexidade dos processos de formação e de mudança.

Neste sentido, a IA pode contribuir para a formação do profissional reflexivo pois permite a resolução de problemas concretos e um aprofundamento do pensamento em diversas dimensões, o que sustentará a formação contextualizada em grupo e ajudará a consolidar a consciência e força da identidade do corpo profissional dos professores (ALARCÃO, 2002). 
Desta forma, a investigação-ação é utilizada muitas vezes como uma forma de desenvolvimento profissional devendo, contudo, distinguir-se da reflexão sobre a própria prática. Esta distinção pode fazer-se tendo em conta o grau de intencionalidade e a sistematização da reflexão, pois no caso da investigação-ação são requeridos ciclos de planeamento, ação, observação e reflexão, os resultados de um ciclo servem como ponto de partida para o seguinte, e o conhecimento produzido deve ser relevante para a resolução de situações e desenvolvimento profissional dos docentes (ANDERSON; HERR, 2016).

Assim, a IA pode ter como objetivo compreender, melhorar e reformar práticas (EBBUTT, 1985) e consistir na recolha de informações sistemáticas com o objetivo de promover mudanças sociais (BOGDAN; BIKLEN, 1994), envolvendo-se o investigador ativamente na causa da investigação. Num modelo de desenvolvimento profissional através da investigação-ação não deixa de assumir particular relevância o envolvimento dos professores enquanto investigadores da sua própria ação, segundo Oliveira-Formosinho, Azevedo e Mateus-Araújo (2009), pois permite-lhes tornarem-se mais reflexivos nesta perspectiva qualitativa (BOGDAN; BIKLEN, 1994), implicando a mudança social uma alteração de cultura profissional que justifica a abordagem de investigação-ação participada (BELCHIOR, 2013).

A investigação-ação colaborativa gera um processo de formação responsável, capaz de superar rotinas e hábitos estabelecidos e proporcionar uma adequada prática profissional, podendo observar-se uma mudança na forma de abordar as questões, pensar e expressar as experiências que irão influenciar as respostas, tendo por base uma visão da educação como processo de pesquisa, autonomia e responsabilidade (SEPÚLVEDA; CALDERÓN; RUIZ; BELTRÁN, 2008).

Elliott (2010) considera também que a investigação em educação deve constituir-se como uma realização ética associada ao bem educacional e ser suportada por uma intencionalidade prática para a mudança, geradora de competências que habilitem as pessoas a coordenar as suas ações para assistir aos propósitos da práxis.

Deste modo, a IA alterna a ação e reflexão crítica, num processo cíclico ou em espiral, em que são aperfeiçoados de modo contínuo os métodos, os dados e a interpretação à luz da experiência obtida (DICK, 2002). Assim, através da ação desenvolvida e da reflexão sobre esta e os seus resultados, procura-se aprimorar os métodos e as novas ações a desenvolver nos ciclos seguintes, com o intuito de promover a inovação e a melhoria dessa ação (FONSECA, 2013).

De acordo com o texto fundamental de Lewin $(1946,1948)$ que codifica a investigaçãoação em quatro etapas fundamentais: o planeamento, a ação, a observação e a reflexão (citado em COHEN ET AL., 2000), a planificação começa com uma ideia geral da situação presente 
para identificar um objetivo e decidir sobre os primeiros passos a desenvolver, que podem modificar o plano ou ideia original. Na fase seguinte implementa-se o plano e, em seguida, recolhe-se a informação para avaliar a ação realizada, indicando os resultados. Após reflexão sobre estes, é possível planear adequadamente a etapa seguinte com as modificações necessárias ao plano, de forma a captar uma nova visão de conjunto deste.

Kemmis e McTaggart (1988) enfatizam os passos da investigação-ação, referindo que, na prática, o processo inicia-se com a ideia geral de que a mudança é desejável, o campo de ação está definido e as suas circunstâncias são conhecidas, sendo assim desenhado o plano de ação geral. Após se decidir como monitorizar os seus efeitos, este plano é então dividido em vários passos. Ao implementá-los, novos dados surgem, podendo os efeitos da ação ser descritos e avaliados. O plano geral pode também ser revisto face a nova informação e o segundo passo é então planeado com os procedimentos de monitorização apropriados. Após este ser implementado, monitorizado e avaliado, retoma-se a espiral de ação, monitorização e avaliação, continuando o replanejamento sucessivamente.

Desta forma, a IA constitui-se como um processo que se desenvolve em espiral com diferentes círculos de planificação, ação e investigação, em que os três momentos da espiral se concretizam através do diagnóstico da realidade, da formulação de políticas para orientar a ação e do estudo da mudança para melhor compreensão das condições em que os processos ocorrem, segundo Thelen (1967) citado em Silva (1996).

Num diálogo de paradigmas, como expressa Caetano (2004a), que cruza processos de investigação com traços de uma abordagem interpretativa e, em simultâneo, de uma abordagem crítica de transformação da ação para a construção do conhecimento, podem estabelecer-se processos de investigação-formação, que procuram a regulação e transformação da formação com efeitos na transformação da própria investigação. Ou seja, estes processos passam por uma reflexão conjunta entre todos os intervenientes sobre os próprios processos de investigação e formação e pela transferência e adaptação de conhecimentos, procedimentos e hipóteses entre as situações. Neste processo de investigação-formação, os indivíduos são a principal fonte de informação, estudando-se

[...] as suas interpretações acerca das suas próprias mudanças e as suas atribuições causais relativamente aos fatores e processos pelos quais se operaram essas mudanças (...) num posicionamento de comprometimento com o conhecimento que se constrói, onde as interpretações dos sujeitos são também criticamente reconceptualizadas pelo investigador. (CAETANO, 2004a, p.105)

Desta forma, o modelo de investigação-ação pode trazer benefícios no campo educativo, nomeadamente para os professores, promovendo o seu desenvolvimento profissional, pois 
permite uma reflexão na e sobre as suas práticas, com a possibilidade destes construírem conhecimento, participarem ativamente nos processos de ensino e assumirem responsabilidades nessa tomada de decisões, tendo em conta "a necessidade de a escola se assumir como uma instituição aprendente e promover um processo de aprendizagem contextualizado e significativo, potenciador do desenvolvimento do aluno enquanto cidadão ativo e crítico" (FONSECA, 2013, p.84).

No que respeita à recolha e tratamento dos dados qualitativos provenientes da investigação-ação, normalmente de inquéritos por entrevista, questionários com perguntas abertas, e notas ou diários de campo de observação participante ou não participante, será relevante estes serem sujeitos à técnica de análise de conteúdo.

O processo de análise começa com a organização sistemática dos dados. Após a sua organização, deverá proceder-se à sua “divisão em unidades manipuláveis, síntese, procura de padrões, descoberta de aspetos importantes do que deve ser apreendido e a decisão do que vai ser transmitido aos outros" (BOGDAN; BIKLEN, 1994, p. 225).

Paralelamente podem ser usadas outras estratégias de verificação, como uma atitude de permanente questionamento e autorresponsabilização (MILES; HUBERMAN, 1994) ou processos de feedback (YIN, 2011) e comprovação de dados pelos participantes (LINCOLN; GUBA, 1985), ou um sistema de codificação por categorias e indicadores construído, através da definição de unidades de sentido e posteriormente analisadas através de tabelas de frequência (BARDIN, 2001).

Esta codificação dos dados pode ser realizada por indução de regularidades e padrões, num processo de análise iterativo com o auxílio de softwares, como o webQDA ou o NVivo. Nomeadamente, este último ${ }^{1}$ apresenta um conjunto de ferramentas que permite um apoio significativo no tratamento e análise de dados qualitativos, designadamente com um incremento na eficácia e eficiência da sua apreensão sem perder o acesso à fonte dos dados e seu contexto, contribuindo para uma análise mais rigorosa dos dados (JACKSON; BAZELEY, 2007).

Seguindo Bardin (2011), deverá obedecer-se a regras na definição das categorias de fragmentação, considerando que estas devem ser: homogéneas, não misturando temas; exaustivas, esgotando o texto; exclusivas, não se sobrepondo; objetivas, com triangulação no tempo; adequadas e pertinentes, pela adaptação ao conteúdo e objetivos. Ou na tipologia definida por Johnson e Christensen (2014), que referem que as categorias devem ser mutuamente exclusivas, ou distintas, e exaustivas, que classifiquem todos os casos relevantes.

\footnotetext{
${ }^{1}$ NVivo: software (programa de computador) de análise de dados qualitativos, projetado para investigadores trabalharem com dados de texto e/ou multimédia ricos em informação, onde são necessários níveis elevados de profundidade de análise (http://www.qsinternational.com).
} 
Deste modo, o sistema de codificação deverá ser desenvolvido à medida que os dados forem sendo lidos e analisados, percorrendo-se os dados na procura de regularidades e padrões, seguido da escrita de palavras e frases representativas desses padrões de forma a definir as categorias de codificação que permitam classificar depois os dados, por instrumento de recolha de dados (sejam dados de entrevistas ou notas de campo, por exemplo).

Assim, a análise categorial permite, a partir dos dados recolhidos, a classificação e recenseamento pela frequência de presença de itens de sentido, permitindo a interpretação e inferência de conhecimento, pela dedução lógica através da análise dos resultados.

De acordo com Flick (2005), a análise de conteúdo qualitativa é um procedimento de análise de material escrito, com a utilização de categorias aplicadas ao material empírico, que não são necessariamente extraídas dele, mas repetidamente são confrontadas com este e modificadas sempre que necessário, tendo como objetivo a redução do material para posterior tratamento e análise.

Neste processo, partindo das questões e dados que se pretendem interpretar e definidas as unidades de sentido, os textos a tratar deverão ser codificados e extraídas as matrizes de frequência por categorias e indicadores (preferencialmente através de um software de análise qualitativa de dados). A seguir deverá ser efetuada uma análise de conteúdo sintetizadora, em que o material será parafraseado e serão agrupadas e reduzidas as passagens semelhantes, saltando-se as passagens menos relevantes com o mesmo significado, num procedimento de condensação das afirmações em formulações mais gerais no sentido de um maior nível de abstração. Pode também ser utilizada a análise de conteúdo explicativa, retirando-se afirmações do texto para explicar as passagens a analisar, e ainda a análise de conteúdo estruturante, na procura de estruturas formais do material (MAYRING, 1983, citado em FLICK, 2005), extraindo do software utilizado, relatórios de síntese por categoria e indicadores, a seguir resumidos em texto, o que permitirá dar maior relevância aos factos ou ideias mais frequentes ou mais significativas para as questões em estudo.

Segundo Bogdan e Biklen (1994), os investigadores da investigação-ação recolhem os dados com o objetivo de modificar as práticas existentes pelo que devem procurar ser exaustivos na pesquisa de materiais de documentação de forma a puderem sugerir recomendações para a mudança, questionando continuamente essa mesma documentação, visto muitas vezes, esta ser baseada nas "palavras" das pessoas, consideradas como dados qualitativos.

Em suma, a análise de conteúdo consiste numa técnica de pesquisa documental, importante na IA, que procura organizar num conjunto de categorias de significação, o conteúdo manifestado, de diversos tipos de comunicações (entrevistas ou documentos de natureza 
variada), com o propósito de proceder à descrição objetiva, sistemática e, eventualmente quantitativa de tais conteúdos, incidindo "sobre as denotações (o primeiro sentido do discurso) e não sobre as conotações (reflexo dos pontos de vista subjetivos de quem fala ou escreve)" (AMADO, 2014, pp.302-303), imprimindo rigor, cientificidade e validação à investigação.

\section{Metodologia}

A metodologia deste estudo baseou-se numa revisão de literatura e análise de um caso, no qual foi aplicada a metodologia de investigação-ação no contexto educacional (RODRIGUES, 2017). Dentro da perspectiva epistemológica definida, na dimensão da intervenção, a investigação-ação foi considerada como modelo central, através da implementação de um projeto de investigação-formação desenvolvido em contexto de trabalho numa comunidade educativa específica com um programa desenhado de formação ativa com integração das tecnologias digitais na escola.

Este projeto centrou-se nas práticas dos professores numa perspectiva de formação e desenvolvimento profissional e pessoal, pretendendo promover a reflexão conjunta com vista à construção de competências e inovação de metodologias e estratégias pedagógicas através de experiências e atividades realizadas pelos professores com os seus alunos.

No processo de investigação-ação (IA) foram consideradas duas dimensões: uma dimensão Macro, que englobou três ciclos de IA que corresponderam a três anos letivos e uma dimensão Micro, de implementação do projeto de investigação-formação, que decorreu dentro do $2 .^{\circ}$ e $3 .^{\circ}$ Macro Ciclos do mesmo processo, correspondendo cada Micro Ciclo a um período letivo e à implementação de uma ação/oficina de formação (ver Figura 1).

Figura 1 - Macro Ciclos e Micro Ciclos do processo de investigação-ação

MACRO CICLOS

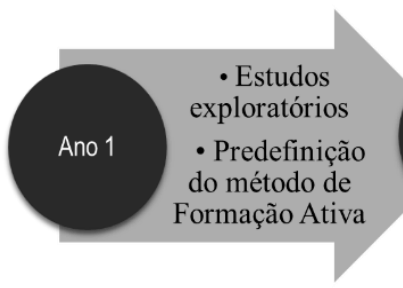

MICRO CICLOS
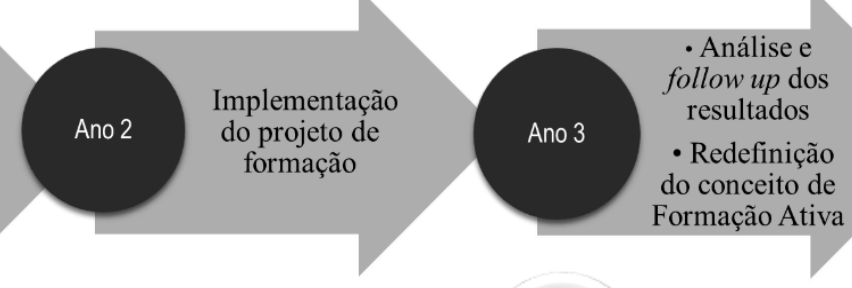

$1 .{ }^{\circ}$ periodo

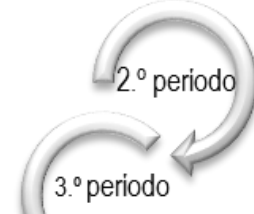

Oficina de formação 1
Oficina de formação 3

Oficina de

formação 2 
Neste processo de investigação-ação assumiu um peso significativo a técnica de análise de conteúdo, aplicada no tratamento e análise dos dados qualitativos, provenientes dos textos das entrevistas realizadas, diários de campo e reflexões dos professores. Esta técnica, segundo Bardin (2011), engloba um conjunto de instrumentos metodológicos, em constante aperfeiçoamento, que se aplicam a discursos e conteúdos diversificados, numa hermenêutica controlada baseada na dedução e inferência, que permitem o cálculo de frequências que fornecem dados cifrados, passíveis de facilitar a interpretação.

\section{Instrumentos de recolha de dados}

Os diários de campo ou diários de investigação (SILVERMAN, 2009) constituíram-se como instrumentos essenciais na recolha de dados da observação participante, pois permitiram documentar o processo de abordagem do terreno, as experiências ocorridas e consequentes reflexões, e sobretudo possibilitaram a incorporação das perspetivas, neste caso de duas formadoras, uma dela a investigadora, que desenvolveram em par pedagógico, as duas primeiras oficinas de formação. A última, foi desenvolvida apenas pela investigadora.

O diário de campo foi iniciado no $1 .^{\circ}$ Macro Ciclo, desde o início do trabalho de campo, e foi concluído no final do projeto de investigação-formação. Devido à sua extensão, foi dividido em três partes, aquando do tratamento dos dados, para organizar de forma mais coerente e facilitar a análise de conteúdo efetuada ao longo dos Micro Ciclos.

As descrições e reflexões efetuadas durante o desenvolvimento das oficinas de formação, incidiram sobre: os relatos e comportamento dos sujeitos; as afirmações e reflexões dos professores; e o ambiente e a cultura organizacional da sala de formação e da escola. Tiveram como foco, ao longo do processo de formação, a formação em ação, os métodos e técnicas pedagógicas utilizadas, a utilização e integração das tecnologias digitais, e os recursos educativos digitais (RED) criados.

Salienta-se o facto de o diário de campo ter sido elaborado pela investigadora em conjunto com a formadora, tendo esta também colaborado depois no processo de análise de conteúdo. A recolha das notas foi efetuada maioritariamente pela formadora no decorrer das sessões de formação enquanto a investigadora a ministrava. Por sua vez, nas horas seguintes esta reescreveu-as e pormenorizou-as, acrescentando as respetivas reflexões, seguindo as recomendações de Bogdan e Biklen (1994), nomeadamente: não deixando passar tempo entre a observação e registo; efetuando com tempo a pormenorização dos acontecimentos cronologicamente; e acrescentando notas sempre que a memória as trouxe do esquecimento. 
Segundo Miles e Huberman (1994), na pesquisa qualitativa, as questões de validade e confiabilidade dos instrumentos são influenciadas em grande parte pelas competências do investigador. Deste modo, assume elevada importância a forma como os dados são recolhidos e os instrumentos são usados por este, recaindo sobre si mesmo e sobre os seus colegas na investigação, esta responsabilidade.

A análise de conteúdo das quatro entrevistas exploratórias foi realizada de acordo com as categorias de análise predefinidas e construção de um plano de análise de conteúdo, com os respetivos resultados apresentados com base na frequência de referências por categorias e indicadores.

Relativamente à análise dos dados, na realização da análise de conteúdo, seguindo Bardin (2011), iniciámos a pré-análise com a leitura e organização do material recolhido, e com a preparação formal deste material, reunindo-o primeiramente num ficheiro de Word, para ser a seguir categorizado, codificado e tratado no software NVivo.

Segundo esta autora, esta fase da análise de conteúdo, tem por objetivo tornar operacionais e sistematizar as ideias iniciais de forma a delinear um plano de análise preciso, mas flexível. A fase seguinte, de exploração do material, consiste na aplicação sistemática das decisões tomadas na fase anterior de categorização e codificação, para que na terceira fase, seja possível efetuar o tratamento dos resultados, a inferência ou indução e a interpretação dos dados.

Enquanto a codificação corresponde a uma transformação dos dados em bruto de forma a permitir uma representação do conteúdo ou da sua expressão, a categorização permite a classificação de elementos de um conjunto por diferenciação, e seguidamente, por reagrupamento segundo um determinado tipo ou analogia, sendo as categorias, classes que reúnem um grupo de elementos com caraterísticas comuns (unidades de registo) com um determinado título genérico (BARDIN, 2011).

Por outras palavras, trata-se de uma análise de dados em que se segmenta o texto em unidades de sentido, o que pode corresponder a uma palavra, uma frase ou várias, para posteriormente os codificar em categorias (JOHNSON; CHRISTENSEN, 2014), sendo os códigos designações, neste estudo, palavras ou expressões criadas de forma indutiva, para atribuição de significado às unidades de sentido, de forma a poder organizar a informação e analisar regularidades (MILES; HUBERMAN, 1994).

$\mathrm{Na}$ análise de conteúdo realizada neste projeto de investigação-formação foi escolhido o critério de categorização semântico, por categorias temáticas, tendo sido adotado um sistema de categorias, resultante de uma classificação analógica e progressiva dos elementos do texto. 
Tratou-se de um processo por "acervo" com uma organização e reagrupamento progressivo das categorias para que estas possuíssem as qualidades desejadas, de: exclusão mútua, em que cada elemento não deve existir em mais do que uma divisão; homogeneidade, na classificação da sua organização; pertinência, adaptada ao material recolhido e pertencente ao quadro teórico definido; objetividade e fidelidade, evitando a subjetividade dos codificadores através da sua triangulação; e produtividade, pela riqueza dos resultados produzidos (BARDIN, 2011).

\section{Processo de análise dos dados}

$\mathrm{Na}$ análise dos dados, após identificação das categorias, a inferência ou indução para a interpretação dos dados, foi efetuada pela técnica de análise categorial, o desmembramento do texto em unidades ou categorias numa análise temática que posteriormente formou o sistema de classificação por categorias (BARDIN, 2011; JOHNSON; CHRISTENSEN, 2014).

À medida que este trabalho foi realizado e as unidades de dados foram sendo categorizadas, estas categorias foram sendo continuamente reformuladas. Ou seja, a primeira versão das categorias de codificação dos dados tratou-se, na realidade, de um teste de viabilidade às categorias criadas, na medida em que estas foram sendo modificadas, surgindo novas categorias e sendo eliminadas outras (BOGDAN; BIKLEN, 1994).

Desta forma podemos resumir da seguinte forma o processo de análise de conteúdo realizado:

1. ${ }^{\circ}$ Leitura exploratória de todos os dados recolhidos;

2. ${ }^{\circ}$ Predefinição de categorias e indicadores de cada instrumento (entrevistas, diários de campo e reflexões dos professores);

3. ${ }^{\circ}$ Codificação dos dados, instrumento a instrumento, com reajuste contínuo de categorias e indicadores;

4. ${ }^{\circ}$ Leitura das unidades de sentido, indicador a indicador, e respetiva recategorização, quando necessário;

5. ${ }^{\circ}$ Reformulação das categorias e indicadores devido ao cruzamento das categorias e indicadores dos diferentes instrumentos de recolha de dados;

6. ${ }^{\circ}$ Leitura de revisão final (após cerca de três meses do passo anterior), indicador a indicador, e respetiva recategorização de algumas unidades de sentido;

7. ${ }^{\circ}$ Construção e análise de matrizes de frequência, por instrumento; 
8. ${ }^{\circ}$ Resumo da informação, interpretação e inferência dos resultados obtidos através das matrizes de frequência e relatórios por categoria e indicadores (extraídos do software NVivo);

9. ${ }^{\circ}$ Construção de matrizes de análise de frequências com cruzamento de instrumentos, pelas principais categorias e indicadores;

10. Análise geral, interpretação, síntese e inferência dos resultados obtidos.

Acrescenta-se que, nos diferentes instrumentos, se procuraram definir as mesmas categorias para permitir no final um cruzamento geral de todos os dados, codificando-se ainda dimensões de análise comuns com correspondência às categorias definidas.

Seguindo os tipos de categorias elaborados por Bogdan e Biklen (1994), diversos foram considerados:

- códigos de contexto, com uma categoria e indicador nomeado de Contexto;

- códigos de definiçãa da situação, caso da categoria Utilização;

- perspetivas tidas pelos sujeitos, com a categoria Visão e Formação de professores;

- pensamentos dos sujeitos sobre pessoas e objetos, caso das categorias Atitudes dos professores, Efeitos das tecnologias e Avaliação da utilização;

- códigos de processo, como o da categoria Desenvolvimento de conhecimentos e competências;

- códigos de atividade, caso das categorias Atividades desenvolvidas e Recursos e ferramentas digitais utilizadas;

- códigos de estratégia, com a categoria Metodologias e estratégias;

- códigos de acontecimentos, caso das categorias Modelo e método de Formação.

\section{Interpretação dos dados e matrizes de análise de frequências}

No que respeita à análise geral e interpretação dos dados, foi possível extrair matrizes de frequências que permitiram obter informação de forma mais facilitada e rigorosa. Por exemplo, em relação às entrevistas exploratórias, pudemos resumir que,

[...] em termos gerais, a maior frequência de respostas recaiu sobre a forma como são utilizadas as tecnologias digitais $(28,8 \%)$ sobretudo no seu uso com os alunos e enquanto professores, indo ao encontro de um dos principais objetivos das entrevistas. Também a visão geral dos professores, nomeadamente quanto à utilidade e potencialidades das tecnologias se evidenciou (19,5\%), seguida do tipo de utilização efetuada com os recursos e ferramentas $(12,7 \%)$, metodologias e estratégias usadas $(11,0 \%)$, e ainda, sobre os efeitos desta utilização das tecnologias digitais (11,9\%), especialmente no processo de ensino-aprendizagem e motivação. Foram ainda abordados outros aspetos como as atitudes favoráveis ou de resistência dos 
professores face às tecnologias $(6,8 \%)$, a necessidade de avaliar a sua utilização $(1,7 \%)$, a relevância e benefício da formação de professores nesta área $(4,2 \%)$ e que tipo de formação seria a mais adequada para este efeito $(3,4 \%)$. (RODRIGUES, 2017)

No caso dos diários de campo e reflexões, a partir da análise de conteúdo realizada foram destacadas quatro categorias com intercepção dos dados das três oficinas, incluindo a perspectiva das formadoras (através dos diários de campo) e a perspectiva dos professores formandos (através das suas reflexões). As categorias mais relevantes foram: Metodologias $e$ estratégias, Atividades desenvolvidas, Modelo e método de formação e Desenvolvimento de conhecimentos e competências, tendo sido geradas matrizes de análise de frequências por categorias, indicadores e instrumentos de recolha de dados

A título de exemplo, na categoria Metodologias e estratégias, podemos verificar um total de 311 referências nos diários de campo (178) e reflexões dos formandos (133) relativas às três oficinas de formação, conforme o Quadro 1.

Quadro 1 - Frequência de referências na categoria Metodologias e estratégias nas três oficinas

\begin{tabular}{|c|c|c|c|c|c|c|}
\hline Metodologias e estratégias & \multicolumn{2}{|c|}{ Diários de campo } & \multicolumn{2}{|c|}{$\begin{array}{l}\text { Reflexões dos } \\
\text { formandos }\end{array}$} & \multicolumn{2}{|c|}{ Total } \\
\hline \multirow{9}{*}{$\begin{array}{l}\text { Com tecnologias digitais }(\operatorname{Pr} 1) \\
\text { Usadas com os alunos (Pr1) } \\
\text { Transversal ou interdisc. }(\operatorname{Pr} 1) \\
\text { Ensino diferenciado }(\operatorname{Pr} 2) \\
\text { Relação pedagógica (Pr3) } \\
\text { Trab. colaborativo e coop. (Pr4) } \\
\text { Metodologias ativas (Pr4) } \\
\text { Trabalho extra-aula (Pr4) } \\
\text { Construção conhecimento (Pr5) }\end{array}$} & 44 & $25 \%$ & 30 & $23 \%$ & 74 & $24 \%$ \\
\hline & 2 & $1 \%$ & 12 & $9 \%$ & 14 & $5 \%$ \\
\hline & 4 & $2 \%$ & 5 & $4 \%$ & 9 & $3 \%$ \\
\hline & 30 & $17 \%$ & 14 & $11 \%$ & 44 & $14 \%$ \\
\hline & 10 & $6 \%$ & 4 & $3 \%$ & 14 & $5 \%$ \\
\hline & 35 & $20 \%$ & 30 & $23 \%$ & 65 & $21 \%$ \\
\hline & 22 & $12 \%$ & 27 & $20 \%$ & 49 & $16 \%$ \\
\hline & 21 & $12 \%$ & 8 & $6 \%$ & 29 & $9 \%$ \\
\hline & 10 & $6 \%$ & 3 & $2 \%$ & 13 & $4 \%$ \\
\hline Totais & 178 & $100 \%$ & 133 & $100 \%$ & 311 & $100 \%$ \\
\hline
\end{tabular}

Fonte: Rodrigues (2017)

Deste modo, foi possível ter acesso a esta matriz de análise de frequências conjuntamente com a informação disponibilizada de forma desagregada no software NVivo, que pudemos consultar em simultâneo com a análise das tabelas de frequência, o que nos permite com maior facilidade e rapidez, efetuar interpretações rigorosas dos dados qualitativos.

Neste caso, pudemos extrair informação que nos permite dizer que foram encontradas diversas referências sobre o uso de softwares com apoio da Internet, que proporcionaram a utilização de metodologias e estratégias de trabalho diversificadas, como a criação de grupos de trabalho online, a partilha de materiais e informação, a visualização de pequenos vídeos, a criação de eventos e calendarização de apresentações, a promoção de um fórum de debate, a exploração de softwares vários nas sessões, a elaboração de instrumentos de avaliação, a criação 
de webquests, a disponibilização ou criação de tutoriais com utilização do vídeo para a criação de microaulas, a realização de sessões síncronas e de uma videoconferência com um convidado e, entre outras, a possibilidade de esclarecimento de dúvidas online extra aula aos alunos.

Sobre as atividades com integração das tecnologias digitais desenvolvidas com maior frequência pelos professores neste projeto e que suscitaram uma adesão significativa foram a: construção de quizzes, mapas conceptuais e flash cards com a ferramenta GoConqr; criação de grupos e páginas no Facebook e de sites no software Wix; elaboração de fichas de trabalho no Google Forms; criação de e-books com os alunos, utilizando as ferramentas Calaméo, Story Bird e Blurd Book Wright; construção de textos e criação de personagens no Voki; sendo ainda o uso de email, referido por diversos professores. Menciona-se também, a criação pelas formadoras de um grupo fechado no Facebook que se manteve ao longo de todo o projeto de formação, pretendendo-se que tivesse continuidade após o seu término.

Relativamente às Atividades desenvolvidas pelos professores formandos ao longo das três oficinas de formação, salienta-se que foram estes que criaram e escolheram as atividades que depois desenvolveram com os seus alunos, tendo alguns professores conjugado várias atividades com tecnologias em simultâneo.

Sobre as características do Modelo e método de formação utilizado, pudemos confirmar o enriquecimento da formação por incluir docentes de várias áreas curriculares; verificámos a importância da flexibilidade e liberdade dada aos formandos para escolha das atividades e projetos a desenvolverem na sua motivação e desenvolvimento de competências, assim como, da diferenciação permitida pelo método de formação; e verificámos que o apoio das formadoras, numa perspectiva de consultoria, foi um fator facilitador no uso das tecnologias digitais.

Quanto ao Desenvolvimento de conhecimentos e competências, pudemos concluir que este foi evidente através dos projetos e atividades com tecnologias digitais realizadas pelos professores com os seus alunos, que promoveu a efetiva experimentação, tendo-se também observado em todos os participantes um efetivo incremento ao nível das competências e integração pedagógica das tecnologias nos seus processos de ensino-aprendizagem, tendo ainda vários professores mencionado a sua intensão de continuar a utilizar e integrar as tecnologias nas suas aulas.

\section{Conclusões}

De forma a evitar a "leitura simples do real" e os perigos da compreensão espontânea, procurando uma atitude de "vigilância crítica", considerou-se como muito relevante a utilização da análise de conteúdo no desenvolvimento da metodologia de investigação-ação, que responde 
aos objetivos de superação da incerteza e do enriquecimento da leitura dos dados, centrados nos polos: desejo de rigor e necessidade de descobrir além das aparências (BARDIN, 2011).

Segundo esta, a análise de conteúdo possuiu duas funções que podem ser complementares: uma função heurística, que enriquece e aumenta a propensão para a descoberta, e uma função de "administração da prova", servindo as hipóteses ou afirmações provisórias de diretrizes na análise sistemática para serem verificadas no sentido de uma confirmação ou infirmação.

Desta forma, Bardin (2011) completa a noção de análise de conteúdo referindo a possibilidade da utilização de várias operações analíticas que podem enriquecer os resultados ou aumentar a sua validade de forma a obter uma interpretação final fundamentada, e também, o facto de uma análise objetiva poder fundamentar juízos intuitivos através de operações de verificação que conduzem a resultados de confiança.

Silverman (2009) confirma o contributo da análise de conteúdo para a confiabilidade e validade, acrescentando a necessidade de uso de métodos padronizados de registo, preferencialmente efetuados por mais que um pesquisador.

Visto a formação de professores no caso deste projeto de investigação-ação ter sido desenvolvida ao longo de um ano letivo, permitiu o envolvimento prolongado, a observação persistente da investigadora/formadora e a triangulação (GUBA, 1983; LINCOLN; GUBA, 1985). Tal como referido, ao longo do processo de investigação foi realizada sempre que possível e pertinente a triangulação de dados, através da combinação de fontes de dados diversas, de participação e análise por diferentes investigadores e de métodos de recolha de dados diversificados (COHEN ET AL., 2000; DENZIN, 1984; YIN, 2011), sendo utilizada como método de confirmação de resultados, suportados pontualmente em medições independentes concordantes não contraditórias (MILES; HUBERMAN, 1994).

O caso apresentado desenvolvido através de um projeto de investigação-formação numa comunidade educativa verificou-se promover a inovação de metodologias e estratégias pedagógicas com integração das tecnologias digitais utilizadas pelos professores, através da aplicação de um programa de formação ativa de professores, impulsionado pela metodologia de investigação-ação e suportado na análise de conteúdo dos dados qualitativos.

Neste projeto confirmou-se o desenvolvimento de uma cultura mais digital nesta comunidade educativa, alcançando-se os principais objetivos da investigação, designadamente a construção e desenvolvimento de competências, nomeadamente de reflexividade e de autonomia por parte dos professores, a inovação com uma efetiva integração das tecnologias digitais no processo de ensino-aprendizagem e a promoção do desenvolvimento profissional 
docente no contexto da futura sociedade do conhecimento, constando-se a adequação da metodologia de investigação.

\section{REFERÊNCIAS}

ALARCÃO, Isabel. Escola reflexiva e desenvolvimento institucional: que novas funções supervisivas? In: OLIVEIRA-FORMOSINHO, Júlia, A supervisão na formação de professores: da sala à escola, p.212-238. Porto: Porto Editora, 2002.

AMADO, João. Manual de investigação qualitativa em educação. Coimbra: Imprensa da Universidade de Coimbra, 2014.

ANDERSON, Gary L.; HERR, Kathryn. O docente-pesquisador: a investigação-ação como uma forma válida de geração de conhecimentos. Revista Interinstitucional Artes de Educar, Rio de Janeiro, v. 2, n.1, Artes de ser professor, p. 4-24, fev-mai 2016. Disponível em: www.e-publicacoes.uerj.br/index.php/riae/article/download/21236/17839. Acesso em: 3 abr. 2021

BARDIN, Laurence. Análise de conteúdo. Lisboa: Edições 70, Lda., 2011. (Original publicado em francês em 1977: L'Analyse de Contenu).

JACKSON, Kristi; BAZELEY, Pat. Qualitative Data Analysis with NVivo. London: SAGE Publications Ltd., 2007.

BELCHIOR, Margarida Maria. Aprender na sociedade da informação e do conhecimento - entre o local e o global - contributos para a Educação para a Paz. Tese (Doutorado em Educação, especialidade TIC na Educação). Lisboa. Instituto de Educação da Universidade de Lisboa, 2013. Disponível em: http://hdl.handle.net/10451/8005. Acesso em: 8 mar. 2021

BERA (British Educational Research Association). Ethical Guidelines for Educational Research, fourth edition, London, 2018. Disponível em: https://www.bera.ac.uk/publication/ethical-guidelines-for-educational-research-2018. Acesso em: 4 fev. 2021.

BLUMER, Herbert. El interaccionismo simbólico. Perspectiva y método. Barcelona: Hora S.A. 1982 (Original publicado em inglês em 1969: Symbolic Interactionism Perspective and Methods).

BOGDAN, Robert C.; BIKLEN, Sari Knopp. Investigação qualitativa em educação. Uma introdução à teoria e aos métodos. Porto: Porto Editora, 1994.

CAETANO, Ana Paula. Para uma conceptualização da reflexão na investigação-acção. Revista Portuguesa de Pedagogia, ano 37-3, p. 113-133, 2003.

CAETANO, Ana Paula. A mudança dos professores pela investigação-acção. Revista Portuguesa de Educação, vol. 17, n. 1, p. 97-118. Universidade do Minho, Portugal, 2004a. 
CAETANO, Ana Paula. Mudança e formação de professores. In: NÓVOA, António (Org.). Currículo, situações educativas e formação de professores: estudos em homenagem a Albano Estrela, p.227-251. Lisboa: Educa, 2004b.

CARVALHO, Virgínia Donizete de.; BORGES, Livia de Oliveira; RÊGO, Denise Pereira do. Interacionismo simbólico: origens, pressuposto e contribuições aos estudos em psicologia social. Psicologia, Ciência e Profissão, v. 30, n. 1, p. 146-161, 2010.

COHEN, Louis; MANION, Lawrence; MORRISON, Keith. Research methods in education, $5^{\text {th }}$ Ed. London and New York: Taylor \& Francis e-Library and Routledge Falmer, 2000 .

COUTINHO, Clara. P.; SOUSA, Adão.; DIAS, Anabela.; BESSA, Fátima; FERREIRA, Maria José; VIEIRA, Sandra. (2009). Investigação-acção: metodologia preferencial nas práticas educativas. Revista Psicologia, Educação e Cultura, Vol. XIII, nº 2, p. 455-479. Instituto de Educação da Universidade do Minho. Disponível em: http://repositorium.sdum.uminho.pt/bitstream/1822/10148/1/Investiga\%c3\%a7\%c3\%a3o_Ac \%c3\%a7\%c3\%a3o_Metodologias.PDF. Acesso em: 13 abr. 2021.

DENZIN, Norman. The research act. Englewood Cliffs, NJ: Prentice Hall, 1984.

DEWEY, John. Experiencia y educación. Buenos Aires: Editorial Losada, S.A., 1960.

DICK, Bob. Action research: action and research. 2002. Disponível em: http://www.aral.com.au/resources/aandr.html Acesso em: 21 mai. 2021.

EBBUTT, David. Educational action research: some general concerns and specific quibbles. In: BURGESS, Robert. (Ed.). Issues in educational research: qualitative methods. London: Falmer Press, 1985.

ELLIOTT, John. Building educational theory through action research. In: NOFFKE, S.; SOMEKH, B. Handbook of Educational Action Research, p.28-38. London: SAGE Publications Ltd, 2010.

ESTRELA, Maria Teresa. Um olhar sobre a investigação educacional a partir dos anos 60. In: ESTRELA, A. (Org). Investigação em educação. Teorias e práticas, p.113-141. Lisboa: Educa e UIDCE, 2007.

FLICK, Uwe. Métodos qualitativos na investigação científica. Lisboa: Monitor - Projectos e Edições, Lda, 2005.

FONSECA, Josélia Mafalda Ribeiro. Investigação-ação como abordagem ao currículo: questões metodológicas e éticas. In SOUSA, F., ALONSO, L., ROLDÃO, M. (Orgs.) Investigação para um currículo relevante, pp. 73-86. Coimbra: Almedina, 2013.

GUBA, Egon G. Criterios de credibilidad en la investigación naturalista. In: GIMENO, J. S.; GÓMEZ, A. P. La enseñanza: su teoría y su práctica, p.148-165. Madrid: Akal, 1983.

GUBA, Egon G; LINCOLN, Yvonna. S. Competing paradigms in qualitative research. In: DENZIN, N. K.; LINCOLN, Yvonna. S. (Eds.). Handbook of qualitative research, p. 105117. Cap. 7. Thousand Oaks, CA: SAGE Publications Inc., 1994. 
JOHNSON, Burke; CHRISTENSEN, Larry. Educational research: quantitative, qualitative, and mixes approaches, $5^{\text {th }}$ Ed. Califórnia: SAGE Publications, 2014.

KEMMIS, Stephen; MCTAGGART, Robin. The action research planner, $3^{\text {rd }}$ Ed. Victoria: Deakin University Press, 1988.

LEWIN, Kurt. Action Research and Minority Problems. Journal of Social Issues, v. 2, n. 4, p. 34-46, 1946. Disponível em: https://doi.org/10.1111/j.1540-4560.1946.tb02295.x. Acesso em: 21 mai. 2021

LINCOLN, Yvonna. S.; GUBA, Egon. G. Naturalistic inquiry. Newbury Park, CA: SAGE Publications, 1985.

LUKAS, J. F. Mujika; SANTIAGO, K. Etxeberria. Evaluación educativa. Madrid: Alianza Editorial, 2004.

MILES, Matthew. B.; HUBERMAN, A. Michael. Qualitative data analysis: an expanded sourcebook, $2^{\text {nd }}$ Ed. California: SAGE Publications, Inc., 1994.

OLIVEIRA-FORMOSINHO, Júlia; AZEVEDO, Ana; MATEUS-ARAÚJO, Mónica. A formação em contexto para a pedagogia-em-participação: um estudo de caso. In: OLIVEIRAFORMOSINHO, Júlia. Desenvolvendo a qualidade em parcerias: Estudos de caso, p.80-98, 2009. Lisboa: Direcção Geral de Inovação e Desenvolvimento Curricular, Ministério da Educação.

GIRALDO-RAMÍREZ, Maria Elena. El interaccionismo simbólico, un enfoque metodológico para la investigación de las TIC en educación. In: Monográfico: Maestría en Educación, vol. I., Agosto-Diciembre, p. 108-112. Medellín: UPB. 2009.

RODRIGUES, Ana Luísa. A formação ativa de professores com integração pedagógica das tecnologias digitais. Tese (Doutorado em Educação, especialidade TIC na Educação). Lisboa. Instituto de Educação da Universidade de Lisboa, 2017. Disponível em: http://hdl.handle.net/10451/28329. Acesso em: 8 mar. 2021

RODRIGUES, P. (1992). A avaliação curricular. In Estrela, A.; Nóvoa, A. (Orgs.) Avaliações em educação: novas perspetivas, Lisboa: Educa, 1992. p.15-72.

RODRÍGUEZ, Carlos Enríque. Didáctica de las ciencias económicas, 2007. Edición electrónica. Disponível em: www.eumed.net/libros/2007c/322. Acesso em: 10 jan. 2021

SCHNETZLER, Roseli Pacheco. A importância da investigação-ação no desenvolvimento profissional docente: critérios para sua adoção em teses de doutorado em Educação. Pesquisa en Punto de Vista, v. 3, n. 2 , p. 1-14, 2019. Disponível em: https://doi.org/10.30705/eqpv.v3i2.1745. Acesso em: 21 mai. 2021

SEPÚLVEDA, María; CALDERÓN, Ignacio; RUIZ, Cristóbal; BELTRÁN, Remedios. La investigación acción participativa una estrategia de formación para transformar la realidad en un centro de reforma juvenil. Investigación en la escuela, n. 65, p.101-112, 2008. Disponível em: https://revistascientificas.us.es/index.php/IE/article/view/7155/6301. Acesso em: 20 dez. 2020 
SILVA, Maria Isabel Lopes. Práticas educativas e construção de saberes: metodologias de investigação-acção. Coleção Ciências da Educação. Lisboa: Instituto de Inovação Educacional, Ministério da Educação, 1996.

SILVERMAN, David. Interpretação de dados qualitativos: métodos para análise de entrevistas, textos e interações. Porto Alegre: Artmed Editora, S.A., 2009.

YIN, R. K. Qualitative research from start to finish. New York: The Guilford Press, 2011.

\section{SOBRE A AUTORA:}

\section{Ana Luísa Rodrigues}

Doutorada em Educação, especialidade TIC na Educação, pela Universidade de Lisboa, Instituto de Educação (IE-ULisboa), Professora Auxiliar no IE-ULisboa - Portugal; Investigadora na Unidade de Investigação e Desenvolvimento em Educação e Formação (UIDEF); Correio eletrônico: alrodrigues@ie.ulisboa.pt

iD https://orcid.org/0000-0001-6648-7956 